\title{
Plano de carreira enquanto estratégia de resistência para a valorização docente no território de identidade do sudoeste baiano
}

\author{
Daniela Oliveira Vidal da Silva ${ }^{1}$ \\ Claudio Pinto Nunes ${ }^{2}$
}

\section{RESUMO}

O presente estudo busca fazer uma análise dos dispositivos legais que normatizam os Planos de Cargo, Carreira e Remuneração (PCCR's) e que são utilizados para garantir direitos e criar estratégias para a valorização docente. O campo de pesquisa delimitado é o Território de Identidade do Sudoeste Baiano (TISOBA) e o estudo segue o viés metodológico da pesquisa documental. Os resultados encontrados nos permitem inferir que, embora o Plano de Cargo, Carreira e Remuneração seja pensado para ser um elemento legal de luta e resistência em favor da valorização docente, em alguns municípios esse documento ainda não se configura, de fato, como tal, visto que este dispositivo ainda não foi implementado. Além disso, em outros municípios, encontra-se desatualizado, contrariando o que está determinado em algumas legislações brasileiras que normatizam os PCCR's.

Palavras-chave: Valorização docente. Plano de Cargo, Carreira e Remuneração. Lutas.

\section{Career plan as a strategy of resistance for teacher valorization in the southwestern Bahia identity territory}

\section{ABSTRACT}

The present study seeks to make an analysis of the legal provisions that regulate the Position, Career and Remuneration Plan (PCRP) and which

\footnotetext{
1 Mestre do Programa de Pós-Graduação em Educação - PPGED UESB. Membro do Grupo de Pesquisa Didática, Formação eTrabalho Docente (Difort/UESB/CNPq). Pedagoga da Coordenação de Pesquisa e Extensão da Faculdade Santo Agostinho, campus Vitória da Conquista - Bahia. E-mail: danielaovdasilva@gmail.com.ORCID: http://orcid.org/0000-0002-2316-3035

2 Pós-Doutor em Educação pela Universidade Federal de Minas Gerais (UFMG). Doutor em Educação pela Universidade Federal do Rio Grande do Norte (UFRN) tendo realizado Estágio Doutoral na Universidade de Coimbra (UC). Mestre em Educação e Pesquisa, pela Université Du Québec À Chicoutimi (UQAC). Professor Titular da Universidade Estadual do Sudoeste da Bahia e do Programa de Pós-Graduação em Educação. Líder do Grupo de Pesquisa Didática, Formação e Trabalho Docente (Difort/CNPq). E-mail: claudionunesba@hotmail.com. ORCID: http://orcid.org/0000-0003-1514-6961.
} 
are used to guarantee rights and create resistance strategies for teacher valorization. The delimited search field is the Southwestern Bahia Identity Territory (TISOBA) and the study follows the methodological bias of documentary research. The results we have found allow us to infer that, although the Position, Career and Remuneration Plan is thought to be a legal element of struggle and resistance in favor of teacher valorization, in some municipalities this document doesn't work yet, in fact, as such, since this device has not yet been implemented. In addition, in other municipalities, it is out of date, contradicting what is determined in some Brazilian legislations that normalize the PCCR's.

Keywords: Teacher valorization. Position, Career and Remuneration Plan. Struggle.

\section{Plan de carrera como estrategia de resistencia para la valorización docente en el territorio de identidad del sudoeste Baiano}

\section{RESUMEN}

El presente estudio busca hacer un análisis de los dispositivos legales que regulan los Planes de Cargo, Carrera y Remuneración (PCCR's) y que se utilizan para garantizar derechos y crear estrategias para la valorización docente. El marco del área de investigación es el Territorio de Identidad del Sudoeste Baiano (TISOBA) y el estudio sigue el diseño metodológico de la investigación documental. Los resultados encontrados nos permiten inferir que, aunque el Plan de Cargo, Carrera y Remuneración sea pensado para ser un elemento legal de lucha y resistencia a favor de la valorización docente, en algunos municipios ese documento aún no se configura, de hecho, como tal, ya que este dispositivo aún no se ha implementado. Además, en otros municipios, se encuentra desactualizado contrariando lo que está determinado en algunas legislaciones brasileñas que regulan los PCCR's.

Palabras clave: Valorización docente. Plan de Cargo, Carrera y Remuneración. Luchas.

\section{Considerações Iniciais}

O Plano de Carreira é um instrumento legal específico da administração, que define a constituição da carreira, sua estrutura e funcionamento. Nesta perspectiva, o Plano de Carreira estabelece as normas e 
as regras de funcionamento dos cargos, funções e remuneração, define as atribuições, a estrutura da classe, a mobilidade na carreira, os níveis profissionais, a jornada de trabalho, dentre outros aspectos.

No que tange, especificamente, aos planos de carreira dos docentes municipais, vale ressaltar que sua construção se torna mais consistente se a discussão e a reflexão sobre a carreira contam com a participação do coletivo docente de cada município. Desta forma, a definição das diretrizes para o trabalho docente é enriquecida a partir da luta e sinalizações da classe.

Este estudo é parte integrante de uma pesquisa mais abrangente que aqui se apresenta a partir de um recorte sobre o Plano de Cargo, Carreira e Remuneração (PCCR's) como instrumento para a valorização docente no Território de Identidade do Sudoeste Baiano (TISOBA) ${ }^{3}$. Este recorte é feito objetivando reconhecer o instituído neste instrumento legal em cumprimento com o exposto nas legislações brasileiras e o conceito de valorização adotado pela Confederação Nacional de Educação - CONAE 2018 (BRASIL, 2017), como formação inicial e continuada, carreira, remuneração e condições de trabalho e saúde.

A pesquisa realizada empreendeu uma análise dos Planos de Cargos, Carreira e Remuneração (PCCR's) dos vinte e quatro municípios do Território de Identidade do Sudoeste Baiano (TISOBA). A busca pelos Planos ocorreu, inicialmente, nos sites das prefeituras e das câmaras municipais de cada município, todavia, poucos municípios disponibilizam on line as leis que dispõem sobre seus planos, contrariando o que preveem a Constituição Federal de 1988 em seu Artigo 5, Inciso XXXIII e a Lei da Transparência, no 12.527, de 18 de novembro de 2011 (BRASIL, 2011).

Em seguida, o acesso aos dados não disponibilizados nos sites ocorreu através do contato de e-mail e/ou telefone com as prefeituras e/ou secretarias de educação para as quais enviamos solicitação por escrito e, assim, aguardamos as cópias digitais ou impressas do referido documento para análise.

3 É importante observar que o Programa Territórios de Identidade existe somente no estado da Bahia. O conceito de Território de Identidade ( $\mathrm{TI}$ ) surgiu a partir dos movimentos sociais ligados à agricultura familiar e à reforma agrária, com a finalidade de promover o desenvolvimento econômico e social dos Municípios do Estado da Bahia. Segundo o § 1ª, do artigo $1^{\circ}$, do Decreto n 12.354/2010, considera-se Território de Identidade o agrupamento identitário municipal formado de acordo com critérios sociais, culturais, econômicos e geográficos; e reconhecido pela sua população como o espaço historicamente construído ao qual pertence, com identidade que amplia as possibilidades de coesão social e territorial. (BAHIA, 2010). 
Trata-se de uma pesquisa documental, caracterizada "pela busca de informações em documentos que não receberam nenhum tratamento científico" (OLIVEIRA, 2007, p. 69) que, como instrumento de coleta de dados, consegue anular a possibilidade de influência do pesquisador, já que o texto documental se encontra pronto e é preciso aceitá-lo tal como ele se apresenta. Ludke e André (1986, p. 38) chamam a atenção para a importância do uso de documentos em investigações no campo da educação e afirmam também que: "como uma técnica exploratória, a análise documental indica problemas que devem ser mais bem explorados através de outros métodos".

Neste aspecto, realizamos a pesquisa documental, na perspectiva da análise de políticas públicas brasileiras, tomando como instrumentos os Planos de Cargos, Carreira e Remuneração dos municípios que compõem o Território de Identidade do Sudoeste Baiano,com a intencionalidade de verificar os fatores da formação, carreira e remuneração que constituem a valorização docente, conforme definição já apresentada. Vale ressaltar que a categoria "condições de trabalho e saúde docente", que compõe o conceito de valorização adotado, será apresentada e discutida em outro momento.

A delimitação do campo de pesquisa deu-se primeiro pela importância do TISOBA no cenário estadual, graças ao município de Vitória da Conquista ser o terceiro em número de habitantes do estado da Bahia. A influência do município não se limita apenas ao território de identidade, mas se estende a toda região sudoeste do Estado.

Depois, por ser Vitória da Conquista um município importante na formação de professores, já que possui instituições educacionais que firmam esta cidade como um polo de instituições de ensino superior (IES), com universidades estadual e federal e instituições privadas, que ofertam cursos de licenciatura, conforme destaca Silva $(2015$, p. 28):

Em primeiro lugar está a relevância desse espaço para a formação de professores, uma vez que o município de Vitória da Conquista, pertencente ao Território, é um importante centro de formação em nível superior por conta das diversas instituições públicas e privadas existentes que agrega. Esse desenvolvimento na área educacional fez com que muitos moradores das cidades vizinhas migrassem para Vitória da Conquista para terem acesso à formação. 
Estes fatores contribuíram com a escolha do Território de Identidade do Sudoeste Baiano para análise e compreensão das condições de trabalho docente nos municípios que o compõem, a partir da análise dos Planos de Cargos, Carreira e Remuneração e sua contribuição para o processo de valorização dos professores destes municípios.

Figura 1 - Mapa dos atuais limites do Território de Identidade do Sudoeste Baiano com a quantidade de habitantes por município

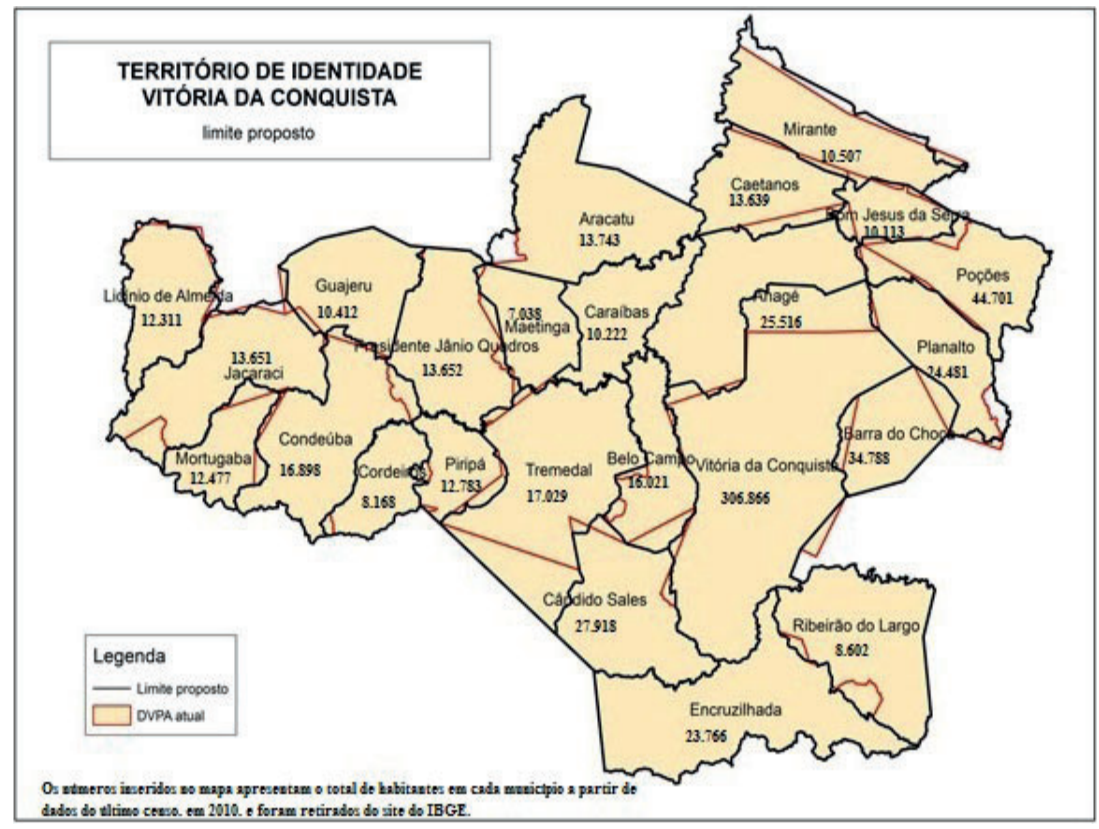

Fonte: SEPLAN/BAHIA, junho de 2011 com acréscimo feito pela autora com os dados do censo de 2010 com a quantidade de habitantes por município retirados do site do IBGE

A figura 1 apresenta os 24 municípios que compõem o Território de Identidade do Sudoeste Baiano e os respectivos números de habitantes de acordo com o Censo Demográfico de 2010 realizado pelo Instituto Brasileiro de Geografia e Estatística (IBGE).

Diante do exposto, buscamos apresentar o que as legislações brasileiras expressam a respeito da elaboração e obrigatoriedade dos planos de cargos, carreira e remuneração e, em seguida, uma breve análise do que está instituído nos PCCR's dos municípios que compõem o TISOBA e, por fim, as considerações finais. 


\section{Planos de Cargo, Carreira e Remuneração: o instituído nas legislações brasileiras}

A Constituição Federal de 1988, em seu Art. 41, parágrafo 10, inciso III, com a redação da Emenda Constitucional no 19/98, trata na introdução desse dispositivo, do entendimento de que para o Estado cumprir seu papel de oferecer serviços públicos de qualidade para a sociedade, precisa avaliar o desempenho dos seus servidores que constituem meio e não fim da atuação estatal. Esta mesma EC n¹9/98, suprimiu a obrigatoriedade da implantação de planos de carreira para todos os servidores públicos, afirmando que essa avaliação tem como finalidade aferir periodicamente o desempenho necessário para a permanência do servidor no cargo ou emprego público, não se articulando obrigatoriamente com a progressão na carreira. Isto nos leva a inferir que esta articulação também não ocorre com os critérios de valorização do profissional, já que este critério de avaliação, nesta configuração, se torna um meio de permanência ou de exoneração para o servidor público.

Porém, em se tratando dos profissionais da educação, vale salientar que no Art. 206, inciso IV da Constituição Federal de 1988, os profissionais do magistério são tratados de forma diferenciada ao dispor quanto à garantia de planos de carreira para o magistério público. Isto implica dizer que um mesmo dispositivo legal pode referir-se de formas diferenciadas para cada profissional.

A Lei de Diretrizes e Bases da Educação Nacional, Lei n`9.394/1996, em seu art. 67, estabelece que estatutos e planos de carreira garantam o ingresso no magistério por concurso público, o aperfeiçoamento profissional, inclusive garantindo a licença remunerada, o piso salarial, a progressão na carreira baseada na titulação e na avaliação de desempenho, uma carga de trabalho que contemple período reservado para estudos, planejamento e avaliação e condições de trabalho adequadas.

Ainda em 1996, a Emenda Constitucional no 14/96 (BRASIL, 1996b) estabeleceu que, nos dez primeiros anos de sua vigência, os entes federados deveriam buscar garantir uma remuneração digna aos profissionais do magistério. Desta forma, a Lei no 9.424/96 (BRASIL, 1996c), que regulamentou o Fundo de Manutenção e Desenvolvimento do Ensino Fundamental e de Valorização do Magistério (FUNDEF), em consonância com o estabelecido na EC 14/96 (BRASIL, 1996b), reiterou que $60 \%$ dos recursos do Fundo fossem destinados à remuneração dos 
profissionais do magistério e estabeleceu o prazo de seis meses para que Estados, Municípios e Distrito Federal elaborassem planos de carreira.

Em 1997, foi a Resolução CNE/CEB nº 03 que fixou as Diretrizes para os Planos de Carreira e Remuneração para o Magistério dos estados, do Distrito Federal e dos municípios, de maneira que as especificidades dos profissionais do magistério fossem tratadas (BRASIL, 1997). Este dispositivo legal buscou incentivar a valorização docente, porém, mesmo respaldando-se nos cálculos custo-aluno-qualidade para a valorização salarial destes profissionais, não representou avanços nestes termos.

Esta Resolução, em seu Art. $6^{\circ}$, incisos V e Vl, dispõe que as novas carreiras devem contemplar os seguintes incentivos de progressão por qualificação do trabalho docente:

- a dedicação exclusiva ao cargo no sistema de ensino;

- o desempenho no trabalho, mediante avaliação segundo parâmetros de qualidade do exercício profissional, a serem definidos em cada sistema;

- a qualificação em instituições credenciadas;

- o tempo de serviço na função docente;

- avaliações periódicas de aferição de conhecimentos na área curricular em que o professor exerça a docência e de conhecimentos pedagógicos. (BRASIL, 1997)

O Plano Nacional de Educação, Lei no 10.172/2001, na meta relativa aos planos de carreira para o magistério afirmava que esses planos deveriam assegurar promoção por mérito, ao mesmo tempo em que previa avaliação periódica da qualidade da atuação dos professores, em ação conjunta da União, dos Estados e dos Municípios, nesse caso como mecanismo para a definição de necessidades e características dos cursos de formação continuada (BRASIL, 2001).

Em 2006, a Emenda Constitucional n 53, que criou o Fundo de Manutenção e Desenvolvimento da Educação Básica e de Valorização dos Profissionais da Educação (FUNDEB), retomou a discussão dos planos de carreira, ampliando sua abrangência para os profissionais da educação e não apenas para o magistério (BRASIL, 2006). Em seu Inciso V, do artigo 206, trata da valorização dos profissionais da educação escolar 
como um princípio da educação e garante, na forma da lei, "planos de carreira, com ingresso exclusivamente por concurso público de provas e títulos, aos das redes públicas" de ensino. E traz em seu parágrafo único, que "A lei disporá sobre as categorias de trabalhadores considerados profissionais da educação básica e sobre a fixação de prazo para a elaboração ou adequação de seus planos de carreira, no âmbito da União, dos Estados, do Distrito Federal e dos Municípios." (BRASIL, 2006).

Já em 2007 a Lei no 11.494/2007, que regulamenta o FUNDEB, fixou o prazo de até 31 de agosto de 2007 para o poder público criar o Piso Salarial Profissional Nacional e este prazo não foi cumprido. Foi em 2008 que a Lei $n^{\circ} 11.738$ foi regulamentada, e instituiu o Piso Salarial Profissional Nacional (PSPN) para os profissionais do magistério público da educação básica, em seu artigo 6:

\begin{abstract}
A União, os Estados, o Distrito Federal e os Municípios deverão elaborar ou adequar seus Planos de Carreira e Remuneração do Magistério até 31 de dezembro de 2009 , tendo em vista o cumprimento do piso salarial profissional nacional para os profissionais do magistério público da educação básica, conforme disposto no parágrafo único do art. 206 da Constituição Federal. (BASIL, 2008)
\end{abstract}

No ano de 2009, as Diretrizes Nacionais para os Planos de Carreira e Remuneração dos Profissionais do Magistério da Educação Básica Pública foram definidas por meio da Resolução CNE/CEB n 02 (BRASIL, 2009). A referida Resolução revogou a Resolução CNE/CEB nº 03/97 e, quanto aos planos de carreira, esta Resolução estabeleceu que tais planos deveriam ser "instituídos para todos os profissionais do magistério e, eventualmente, aos demais profissionais da educação".

As Diretrizes de 2009 regulamentam que os Planos de Carreira devem contemplar investimentos custo-aluno para a melhoria na qualidade do ensino; acesso à carreira por concurso público de provas e títulos; remuneração condigna com a Lei do Piso Salarial Profissional Nacional; equiparação salarial como reconhecimento profissional; progressão salarial por incentivos como titulação, experiência profissional, desempenho, atualização e aperfeiçoamento profissional; incentivo à dedicação exclusiva; garantia das horas-atividades; incentivo à formação com o objetivo de melhorar a qualificação e suprir as carências de habilitação profissional na educação; e, apoio técnico e financeiro para melhorar as 
condições de trabalho dos educadores, erradicar e prevenir a incidência de doenças profissionais.

No dia 25 de junho de 2014 foi sancionada pela Presidente Dilma Rousseff a Lei no 13.005 tendo como ementa: Aprova o Plano Nacional de Educação (PNE) e dá outras providências. Esta Lei tem sua vigência prevista pelo período de 10 (dez) anos e em sua Meta 18 tratados planos de carreira para os profissionais da educação, apresentando oito estratégias para seu desenvolvimento. Esta Meta busca,

Assegurar, no prazo de 2 (dois) anos, a existência de planos de carreira para os (as) profissionais da educação básica e superior pública de todos os sistemas de ensino e, para o plano de carreira dos (as) profissionais da educação básica pública tomar como referência o piso salarial nacional profissional, definido em lei federal, nos termos do inciso VIII do art. 206 da Constituição Federal. (BRASIL, 2014)

Diante do exposto, podemos verificar que são muitas as legislações que tratam de garantias para a implementação de Planos de Cargo, Carreira e Remuneração para os profissionais da educação brasileira. Porém, instituir os planos de carreira em cada um dos entes federados é uma luta que tem em si grandes desafios por causa das particularidades de cada localidade e das características próprias de cada nível de ensino. Por isso esta é uma discussão que traz em seu bojo a necessidade de lutas, diálogos, resistências e políticas públicas sólidas que contemplem os profissionais docentes.

\section{Análise dos Planos de Cargos, Carreira e Remuneração: o instituído no TISOBA}

Apesar da grande quantidade de fatores apontados nas legislações para a garantia da valorização docente instituída nos Planos de Cargos, Carreira e Remuneração, é possível estabelecer alguns parâmetros para definir uma carreira atrativa, que, nos estudos realizados pelos autores deste texto, perpassam pela definição da CONAE/2018 explícitos anteriormente nas considerações iniciais deste estudo.

Assim, neste texto, a análise dos PCCR's busca verificar o instituído neste dispositivo legal a partir de sua implementação em cada município e o cumprimento com base no que propõem as legislações brasileiras, 
no que tange à obrigatoriedade deste instrumento para regulamentar e normatizar os critérios para a carreira docente e sua valorização.

Do total de 24 municípios que compõem o Território de Identidade do Sudoeste Baiano (TISOBA), 19 municípios compartilharam cópias dos Planos de Cargos, Carreira e Remuneração (PCCR's) para análise. São eles: Anagé, Aracatu, Barra do Choça, Belo Campo, Bom Jesus da Serra, Caetanos, Cândido Sales, Condeúba, Cordeiros, Encruzilhada, Guajeru, Licínio de Almeida, Maetinga, Piripá, Planalto, Poções, Ribeirão do Largo, Tremedal e Vitória da Conquista. Os municípios de Jacaraci e Mirante ainda não possuem PCCR's e os municípios de Caraíbas, Mortugaba e Presidente Jânio Quadros não disponibilizaram seus Planos para análise e também não forneceram justificativa.

O quadro 1 apresenta os números das Leis, seus respectivos anos de homologação e, ainda, a ementa. É possível observar as diversas formas para se referir a este dispositivo legal.

A partir dos dados apresentados no quadro 1 é possível verificar que os municípios de Anagé (1998), Barra do Choça (2004), Bom Jesus da Serra (2005), Cândido Sales (2001), Encruzilhada (2005), Guajeru (2005) e Planalto (2008) possuem Planos de Cargos, Carreira e Remuneração anteriores à homologação da Lei no 11.378/2008. Esta Lei, em seu Art. 60, fixa o prazo de 31 de dezembro de 2009 para elaboração ou adequação dos seus PCCRs, considerando o cumprimento do piso salarial profissional nacional. Vale ressaltar que estes municípios não cumpriram o quesito adequação dos seus Planos de Carreira indicadas na referida Lei.

Quadro 1: Dados sobre os Planos de Carreira dos Municípios do TISOBA

\begin{tabular}{|c|c|l|}
\hline MUNICÍPIO & $\begin{array}{c}\text { No E ANO } \\
\text { DA LEI }\end{array}$ & \multicolumn{1}{c|}{ DO QUE TRATA A LEI } \\
\hline Anagé & $\begin{array}{c}\text { Lei no } \\
186 / 1998\end{array}$ & $\begin{array}{l}\text { Dispõe sobre o Estatuto e Plano de Carreira } \\
\text { do Magistério Público Municipal de Anagé, } \\
\text { Estado da Bahia, e dá outras providências. }\end{array}$ \\
\hline Aracatu & $\begin{array}{c}\text { Lei no } \\
510 / 2014\end{array}$ & $\begin{array}{l}\text { Dispõe sobre o Estatuto e Plano de } \\
\text { Carreira e Remuneração do Magistério } \\
\text { Público Municipal de Aracatu e dá outras } \\
\text { providências. }\end{array}$ \\
\hline $\begin{array}{c}\text { Barra do } \\
\text { Choça }\end{array}$ & $\begin{array}{c}\text { Lei no } \\
016 / 2004\end{array}$ & $\begin{array}{l}\text { Dispõe sobre o Plano de Carreira e } \\
\text { Remuneração dos Servidores do Magistério } \\
\text { do Município de Barra do Choça }\end{array}$ \\
\hline
\end{tabular}

Continua 


\begin{tabular}{|c|c|c|}
\hline MUNICÍPIO & $\begin{array}{c}\text { No E ANO } \\
\text { DA LEI }\end{array}$ & DO QUE TRATA A LEI \\
\hline Belo Campo & $\begin{array}{l}\text { Lei no } \\
13 / 2010\end{array}$ & $\begin{array}{l}\text { Estabelece o Plano de Cargos e Salários do } \\
\text { Magistério Público do Município de Belo } \\
\text { Campo, institui o respectivo quadro de cargos } \\
\text { e dá outras providências. }\end{array}$ \\
\hline $\begin{array}{c}\text { Bom Jesus } \\
\text { da Serra }\end{array}$ & $\begin{array}{c}\text { Lei no } \\
\text { 065/2005 }\end{array}$ & $\begin{array}{l}\text { Dispõe sobre o plano de carreira e } \\
\text { vencimento dos servidores do Magistério } \\
\text { Público do município de Bom Jesus da Serra e } \\
\text { dá outras providências }\end{array}$ \\
\hline Caetanos & $\begin{array}{c}\text { Lei no } \\
\text { 109/2009 }\end{array}$ & $\begin{array}{l}\text { Dispõe sobre o Plano de Carreira do } \\
\text { Magistério Público Municipal de Caetanos e } \\
\text { dá outras providências. }\end{array}$ \\
\hline $\begin{array}{l}\text { Cândido } \\
\text { Sales }\end{array}$ & $\begin{array}{c}\text { Lei no } \\
12 / 2001\end{array}$ & $\begin{array}{l}\text { Dispõe sobre o Plano de Carreira do } \\
\text { Magistério Público Municipal de Cândido } \\
\text { Sales e dá outras providências }\end{array}$ \\
\hline Caraíbas & \multicolumn{2}{|c|}{ Não compartilhou o documento para a pesquisa } \\
\hline Condeúba & $\begin{array}{c}\text { Lei no } \\
874 / 2013\end{array}$ & $\begin{array}{l}\text { Dispõe sobre reestruturação do Estatuto e } \\
\text { Plano de Carreira do Magistério público e dá } \\
\text { outras providências }\end{array}$ \\
\hline Cordeiros & $\begin{array}{c}\text { Lei } n^{\circ} \\
554 / 2012\end{array}$ & $\begin{array}{l}\text { Dispõe sobre o Plano de Carreira e } \\
\text { Remuneração do Magistério Público } \\
\text { Municipal de Cordeiros }\end{array}$ \\
\hline $\begin{array}{l}\text { Encruzilha- } \\
\text { da }\end{array}$ & $\begin{array}{c}\text { Lei no } \\
858 / 2005\end{array}$ & $\begin{array}{l}\text { Dispõe sobre o Plano de Carreira do } \\
\text { Magistério Público Municipal de Encruzilhada } \\
\text { e dá outras providências }\end{array}$ \\
\hline Guajeru & $\begin{array}{c}\text { Lei } n^{\circ} \\
150 / 2005\end{array}$ & $\begin{array}{l}\text { Estrutura o Plano de Carreira do Magistério } \\
\text { Público Municipal do Ensino Fundamental e } \\
\text { Médio e dá outras providências }\end{array}$ \\
\hline Jacaraci & \multicolumn{2}{|c|}{ Não possui PCCR } \\
\hline $\begin{array}{l}\text { Licínio de } \\
\text { Almeida }\end{array}$ & $\begin{array}{c}\text { Lei no } \\
02 / 2014\end{array}$ & $\begin{array}{l}\text { Dispõe sobre a reestruturação do Plano de } \\
\text { Carreira e Remuneração do Magistério, e dá } \\
\text { outras providências }\end{array}$ \\
\hline Maetinga & $\begin{array}{c}\text { Lei } n^{\circ} \\
063 / 2009\end{array}$ & $\begin{array}{l}\text { Dispõe sobre o Estatuto do Magistério Público } \\
\text { da Educação Infantil e Fundamental de } \\
\text { Maetinga, e dá outras providências }\end{array}$ \\
\hline Mirante & \multicolumn{2}{|c|}{ Não possui PCCR } \\
\hline Mortugaba & \multicolumn{2}{|c|}{ Não compartilhou o documento para a pesquisa } \\
\hline Piripá & $\begin{array}{c}\text { Lei no } \\
0137 / 2012\end{array}$ & $\begin{array}{l}\text { Dispõe sobre o plano de carreira, cargos, } \\
\text { funções públicas e remuneração dos } \\
\text { servidores do magistério do município de } \\
\text { Piripá e dá outras providências. }\end{array}$ \\
\hline
\end{tabular}




\begin{tabular}{|c|c|l|}
\hline MUNICíPIO & $\begin{array}{c}\text { No E ANO } \\
\text { DA LEI }\end{array}$ & \multicolumn{1}{|c|}{ DO QUE TRATA A LEI } \\
\hline Planalto & $\begin{array}{c}\text { Lei no } \\
277 / 2008\end{array}$ & $\begin{array}{l}\text { Dispõe sobre a Aprovação do Plano de Cargos } \\
\text { e Salários do Magistério Municipal de Planalto }\end{array}$ \\
\hline Poções & $\begin{array}{c}\text { Lei no } \\
975 / 2012\end{array}$ & $\begin{array}{l}\text { Dispõe sobre o Plano de Cargos, Carreira, } \\
\text { Funções Públicas e Remuneração dos } \\
\text { servidores do Magistério Público do } \\
\text { Município de Poções. }\end{array}$ \\
\hline $\begin{array}{c}\text { Presidente } \\
\text { Jânio } \\
\text { Quadros }\end{array}$ & Não compartilhou o documento para a pesquisa \\
\hline $\begin{array}{c}\text { Ribeirão do } \\
\text { Largo }\end{array}$ & $\begin{array}{c}\text { Lei no } \\
228 / 2012\end{array}$ & $\begin{array}{l}\text { Regulamenta o Art. 206 da Constituição } \\
\text { Federal, o Art. 60 da Lei Federal no 11.378/08 } \\
\text { e institui o novo Plano de Carreira, Cargos e } \\
\text { Salários dos Profissionais da Educação Pública } \\
\text { Municipal de Ribeirão do Largo, fixa seu } \\
\text { número e níveis de vencimentos, normas de } \\
\text { ascensão funcional e dá outras providências }\end{array}$ \\
\hline Tremedal & $\begin{array}{c}\text { Lei no } \\
15 / 2009\end{array}$ & $\begin{array}{l}\text { Dispõe sobre o Plano de Carreira do } \\
\text { Magistério Público Municipal de Tremedal e } \\
\text { dá outras providências }\end{array}$ \\
\hline $\begin{array}{c}\text { Vitória da } \\
\text { Conquista }\end{array}$ & $\begin{array}{l}\text { Lei no } \\
1.762 / 2011\end{array}$ & $\begin{array}{l}\text { Dispõe sobre o Estatuto do Magistério } \\
\text { Público Municipal e o Plano de Carreira e } \\
\text { Remuneração dos Profissionais da Educação } \\
\text { no Município de Vitória da Conquista, e dá } \\
\text { outras providências. }\end{array}$ \\
\hline
\end{tabular}

Fonte: Elaborado pela autora a partir de dados dos PCCR's fornecidos pelos municípios do TISOBA, 2018

Os municípios de Aracatu (2014), Belo Campo (2010), Condeúba (2013), Cordeiros (2012), Licínio de Almeida (2014), Piripá (2012), Poções (2012), Ribeirão do Largo (2012) e Vitória da Conquista (2011) também estão atrasados em relação ao cumprimento do prazo estipulado pela Lei supracitada, no quesito elaboração do PCCR.

Os dados apresentados revelam e reforçam o descaso histórico para com o cumprimento das legislações brasileiras e, principalmente, as fragilidades das políticas educacionais que se refletem nos critérios para a valorização dos profissionais da educação e, consequentemente, na qualidade do ensino.

Um estudo realizado por Wink (2009) apresenta dados reveladores sobre a falta de Planos de Carreira na maioria dos municípios do 
Rio Grande do Sul no período da pesquisa e defende que a valorização docente é uma condição importante para a qualidade da educação básica e entende a importância de que todos os municípios brasileiros possuam planos de carreira para todo o magistério público, para que este possa contribuir com a melhoria nas condições sociais do trabalho deste coletivo e formular políticas públicas de valorização profissional com a participação dos docentes.

A autora afirma, ainda, que os professores compreendem que o caminho legítimo para a consolidação da valorização docente passa pelos princípios das lutas coletivas, sindicais e associações, que precisam ser fortalecidas em fóruns e conferências de educação e que uma política consolidada de valorização deve englobar a adequação dos planos de cargos, carreira e remuneração de acordo com as legislações.

Trouxemos as contribuições do trabalho de Wink (2009) para salientar que a ausência de PCCR's em dois municípios do TISOBA, a saber, Jacaraci e Mirante, é um dado que pode demonstrar as dificuldades dos docentes destes municípios em se organizarem na luta pela valorização profissional e da qualidade da educação. E, ainda, que a ausência dos PCCR's nestes municípios contradiz os dados do Observatório do PNE, em que afirma que todos os municípios possuem Plano de Cargo, Carreira e Remuneração e, também, as legislações que determinam que os Planos sejam instituídos estipulando prazos que não foram cumpridos.

De acordo com a análise dos Planos, no que tange aos objetivos do documento, foi possível verificar que não existe uniformidade na redação, já que alguns municípios trazem os objetivos e outros os princípios basilares da carreira do magistério público municipal. Sendo que os objetivos versam basicamente sobre a valorização dos profissionais da educação; a qualidade do ensino; a eficiência e a eficácia do sistema educacional do Município; o mais amplo desenvolvimento do educando, preparando-o para o exercício da cidadania, fundamentando o exercício do magistério nos direitos primordiais da pessoa humana; o aumento do padrão de qualidade de ensino, a valorização e a profissionalização dos servidores do Magistério; assegurar a eficiência e a continuidade das ações administrativas e dos serviços públicos, a valorização e a profissionalização do servidor público.

Já os princípios basilares da carreira do magistério público municipal foram apresentados como valores, a saber: liberdade de ensinar, pesquisar e divulgar o saber produzido pela sociedade, por meio 
de um atendimento escolar de qualidade; reconhecimento do valor do profissional de educação, asseguradas as condições dignas de trabaIho e compatíveis com sua tarefa de educador; promoção na carreira; gestão democrática fundada em decisões colegiadas e interação solidária com os diversos segmentos escolares; união de esforços e desejos comuns, expressos na noção de parceria entre escola e comunidade; qualidade de ensino e preservação dos valores regionais e locais, dentre outros.

Observamos também que os municípios de Maetinga e Piripá trouxeram textos iguais (mesmo conteúdo e mesma redação) no que se refere ao Art. $3^{\circ}$, que trata do exercício do magistério, fundamentado nos direitos primordiais da pessoa humana, amparados nos mesmos princípios:

I - liberdade de ensinar, pesquisar e divulgar o saber produzido pela sociedade, através de um atendimento escolar de qualidade;

II - crença no poder da educação que contemple todas as dimensões do saber e do fazer no processo de humanização crescente e de construção da cidadania desejada;

III - reconhecimento do valor do profissional de educação, asseguradas as condições dignas de trabalho e compatíveis com sua tarefa de educador;

IV - garantia da participação dos sujeitos na vida nacional, no que diz respeito ao alcance dos direitos civis, sociais e políticos;

VI - gestão democrática fundada em decisões colegiadas e interação solidária com os diversos segmentos escolares;

VII - conjunção de esforços e desejos comuns, expressos na noção de parceria entre escola e comunidade. (MAETINGA, 2009; PIRIPÁ, 2012)

No aspecto apresentado, o município de Piripá acrescentou outros incisos ao seu Artigo $3^{\circ}$, ampliando os princípios que fundamentam os direitos primordiais da pessoa humana no exercício do magistério público municipal.

Estes dados foram destacados porque demonstram o que vem sendo discutido nos momentos de formação entre educadores pesquisadores: o fato de que os Planos de Cargo, Carreira e Remuneração, desde o início da obrigatoriedade de sua criação, foram, muitas vezes, copiados. O que ocorre é que municípios menores buscaram num mu- 
nicípio maior, de referência, o modelo de PCCR e aplicaram aos seus municípios, muitas vezes, sem a adequação e discussão pertinentes à realidade local. Por isso, alguns municípios vêm sentindo a necessidade de ampliar a abrangências de seus PCCR's e estão rediscutindo o documento no intuito de atualizá-lo, contemplando assim as necessidades locais da classe docente.

O atual contexto político de desvalorização dos profissionais da educação vem favorecendo a urgência das discussões e atualizações dos Planos de Carreira dos docentes municipais, visto que os ataques aos direitos já conquistados estão sendo efetivos em âmbito federal e para que os direitos locais, em cada município do Território de Identidade do Sudoeste Baiano, não seja totalmente esfacelado, faz-se urgente a revisão e a consolidação destes direitos para a valorização docente. Esta luta é diária e a classe precisa se unir em prol da consciência de classe e qualidade da educação pública.

\section{Considerações finais}

Para que a valorização docente ocorra, é importante conhecer os direitos, lutar por eles por meio das forças sindicais e de associações, e, ainda consolidar suas conquistas em documentos legais que fortalecem o coletivo docente, garantem que os direitos conquistados tenham abrangência para todos os profissionais que compõem as redes municipais de ensino do TISOBA.

No âmbito municipal é o Plano de Cargo, Carreira e Remuneração o documento que regulamenta os direitos conquistados pela classe docente e que precisam ser fortalecidos nas discussões em fóruns e conferências de educação, jornadas pedagógicas, momentos formativos, nas lutas ocorridas no dia-a-dia do chão da escola e que configuram instrumentos de resistência pela valorização dos profissionais da educação.

As reflexões aqui suscitadas sobre o instituído nos Planos de Cargos, Carreira e Remuneração como instrumento estratégico de resistência para a valorização docente no Território de Identidade do Sudoeste Baiano nos permitem inferir que alguns municípios não cumprem o estabelecido em legislações brasileiras que regulamentam a carreira docente.

Alguns municípios do TISOBA não cumprem com o exposto na Lei $n^{\circ} 11.378 / 2008$ no que tange ao cumprimento do prazo para ela- 
boração ou adequação dos seus PCCR's, considerando o cumprimento do piso salarial profissional nacional. Os municípios de Anagé, Barra do Choça, Bom Jesus da Serra, Cândido Sales, Encruzilhada, Guajeru e Planalto possuem Planos de Carreira anteriores a 2009 e, por isso, não cumpriram o quesito adequação dos seus Planos de Carreira indicado na referida Lei, o que nos leva a inferir que os piso salarial não foi atualizado, conforme o referido dispositivo legal.

Ainda no que tange à Lei no 11.378/2008, os municípios de Aracatu, Belo Campo, Condeúba, Cordeiros, Licínio de Almeida, Piripá, Poções, Ribeirão do Largo e Vitória da Conquista foram elaborados após a Lei e, por isso, espera-se que estejam cumprindo com o estabelecido na referida Lei.

O pagamento atualizado do Piso Salarial Profissional Nacional no Território de Identidade do Sudoeste Baiano não fora observado neste estudo, o que poderá servir como indicação para futuros estudos. A ausência de Planos de Carreira em dois municípios do TISOBA também alertam para estudos que possam esclarecer os motivos para o não cumprimento do exposto em legislações brasileiras que determinam a elaboração destes dispositivos legais que fortalecem as lutas pela valorização docente.

\section{Referências}

ANAGÉ. Lei Municipal Ordinária nº 186 de 1998. Dispõe sobre o Estatuto e Plano de Carreira do Magistério Público Municipal de Anagé, Estado da Bahia, e dá outras providências. Diário Oficial do Município, Anagé, BA, 31de dezembro de 1998.

ARACATU. Lei Municipal Ordinária n 510 de 2014. Dispõe sobre o Estatuto e Plano de Carreira e Remuneração do Magistério Público Municipal de Aracatu e dá outras providências. Diário Oficial do Município de Aracatu, Aracatu, BA, 18 de dezembro de 2014.

BAHIA. Decreto no 12.354 de 25 de agosto de 2010. Institui o Programa territórios de Identidade da Bahia e dá outras providências. Diário Oficial do Estado da Bahia, Bahia, 25 ago. 2010. Disponível em: http:// www.demacamp.com.br/svo/assets/decreto_2010_12354_instituio-programa-territ\%C3\%B3rios-de-identidade-e-d\%C3\%A 1-outrasprovid\%C3\%AAncias.pdf. Acesso em: 01 jul. 2018 
BARRA DO CHOÇA. Lei Municipal Ordinária nº 016/2004. Dispõe sobre o Plano de Carreira e Remuneração dos Servidores do Magistério do Município de Barra do Choça. Diário Oficial do Município, Barra do Choça, BA, 20 de janeiro de 2004.

BELO CAMPO. Lei Municipal Ordinária $n^{\circ} 13$ de 2010. Estabelece o Plano de Cargos e Salários do Magistério Público do Município de Belo Campo, institui o respectivo quadro de cargos e dá outras providências. Diário Oficial do Município, Belo Campo, BA, 13 dez. 2010.

BOM JESUS DA SERRA. Lei Municipal Ordinária nº 65 de 2005. Dispõe sobre o Plano de Carreira e Vencimento dos servidores do Magistério Público de Bom Jesus da Serra e dá outras providências. Diário Oficial do Município, Bom Jesus da Serra, BA, 2005.

BRASIL. Constituição da República Federativa do Brasil. Brasília, 5 de outubro de 1988. Diário Oficial da União Diário Oficial da União: Brasília, DF, 5 out. 1998a. Disponível em: http://www.planalto.gov.br/ ccivil_03/constituicao/constituicao.htm. Acesso em: 29 out. 2015.

BRASIL. Emenda Constitucional № 19 de 1998. Reforma Administrativa. Modifica o regime e dispõe sobre princípio e normas da Administração Pública, Servidores e Agentes políticos, controle de despesas e finanças públicas e custeio de atividades a cargo do Distrito Federal, e dá outras providências. Diário Oficial da União: Brasília, DF, seção 1 - Eletrônico, p. 1, 5 jun. 1998b.

BRASIL. Emenda Constitucional No 53, 19 de dezembro de 2006. Dá nova redação aos arts. 70, 23, 30, 206, 208, 211 e 212 da Constituição Federal e ao art. 60 do Ato das Disposições Constitucionais Transitórias. Diário Oficial da União: Brasília, DF, 20 dezembro 2006.

BRASIL. Emenda Constitucional №14, de 12 de setembro de 1996. Modifica os arts. 34, 208, 211 e 212 da Constituição Federal e dá nova redação ao art. 60 do Ato das Disposições constitucionais Transitórias. Diário Oficial da União: Brasília, DF, 12 set. 1996b.

BRASIL. Lei 11.494 de 20 de junho de 2007. Regulamenta o Fundo de Manutenção e Desenvolvimento da Educação Básica e de Valorização dos Profissionais da Educação - FUNDEB, de que trata o art. 60 do Ato das Disposições Constitucionais Transitórias; altera a Lei no 10.195, de 14 de fevereiro de 2001; revoga dispositivos das Leis nos 9.424, de 24 
de dezembro de 1996, 10.880, de 9 de junho de 2004, e 10.845, de 5 de março de 2004; e dá outras providências. Diário Oficial da União: Brasília, DF, 21 jun. 2007. Disponível em: http://www.planalto.gov.br/ ccivil_03/_ato2007-2010/2007/lei/l11494.htm. Acesso em 10 jul.17.

BRASIL. Lei 4.024, de 20 de dezembro de 1961. Fixa as Diretrizes e Bases da Educação Nacional. Brasília: DF. 1961. Disponível em:< http://www. planalto.gov.br/ccivil_03/LEIS/L9394.htm>. Acesso em: 10 set. 2016.

BRASIL. Lei da Transparência, n 12.527, de 18 de novembro de 2011. Regula o acesso a informações previsto no inciso XXXIII do art. $5^{\circ}$, no inciso II do $\S 3^{\circ}$ do art. 37 e no $\S 2^{\circ}$ do art. 216 da Constituição Federal; altera a Lei $n^{\circ} 8.112$, de 11 de dezembro de 1990; revoga a Lei $n^{\circ} 11.111$, de 5 de maio de 2005, e dispositivos da Lei no 8.159, de 8 de janeiro de 1991; e dá outras providências. Diário Oficial da União, 18 nov. 2011. Disponível em: http://www.planalto.gov.br/ccivil_03/_ato20112014/2011/lei/l12527.htm. Acesso em: 5 set. 2015.

BRASIL. Lei n. ${ }^{\circ} 9.424$ de 24 de dezembro de 1996. Dispõe sobre o Fundo de Manutenção e Desenvolvimento do Ensino Fundamental e Valorização do Magistério. Diário Oficial da União: Brasília, DF, 26 dez. 1996c. Disponível em: http://www.planalto.gov.br/ccivil_03/leis/L9424. htm. Acesso em 20 ago.2017.

BRASIL. Lei no 10.172 de 9 de janeiro de 2001. Aprova o Plano Nacional de Educação e dá outras providências. Diário Oficial da União: Brasília, DF, 10 dez. 2001. Disponível em: http://www.planalto.gov.br/ccivil_03/ leis/leis_2001/l10172.htm. Acesso em 20 ago.2017.

BRASIL. Lei no 11.738, de 16 de julho de 2008. Regulamenta a alínea "e" do inciso III do caput do art. 60 do Ato das Disposições Transitórias, para Instituiu o Piso Salarial Profissional Nacional para os Profissionais do Magistério Público da Educação Básica. Diário Oficial da União: Brasília, DF, 17 jul. 2008a. Disponível em: http://www.planalto.gov.br/ccivil_03/_ ato2007-2010/2008/lei/l11738.htm. Acesso em: 01 set. 2016.

BRASIL. Lei no 13.005, de 24 de junho de 2014. Aprova o Plano Nacional de Educação - PNE e dá outras providências. Diário Oficial da União: Brasília, DF, edição extra, 26 jun. 2014.Disponível em: http://www. planalto.gov.br/ccivil_03/_ato2011-2014/2014/lei/l13005.htm. Acesso em: 30 agosto. 2016. 
BRASIL. Lei n 9.394, de 20 de dezembro de 1996. Estabelece as diretrizes e bases da educação nacional. Diário Oficial da União: Brasília,DF, 23 dez.1996a. Disponível em: <http://portal.mec.gov.br/arquivos/pdf/ldb. pdf>. Acesso em: 01 set 2015.

BRASIL. Ministério da Educação. CONAE 2018: Documento Referência. Brasília, 2017. Disponível em: http://www.deolhonosplanos.org.br/ wp-content/uploads/2017/04/Documento-ReferenciaCONAE2018.pdf. Acesso em: 10 de dezembro de 2017.

BRASIL. Resolução N.` 3, de 8 de outubro de 1997. Fixa Diretrizes para os Novos Planos de Carreira e de Remuneração para o Magistério dos Estados, do Distrito Federal e dos Municípios. Conselho Nacional de Educação. Disponível em: http://portal.mec.gov.br/cne/arquivos/pdf/ CEB0397.pdf. Acesso em 02 mar. 2015.

BRASIL. Resolução № 2, de 28 de maio de 2009. Fixa as Diretrizes Nacionais para os Planos de Carreira e Remuneração dos Profissionais do Magistério da Educação Básica Pública, em conformidade com o artigo $6^{\circ}$ da Lei no 11.738, de 16 de julho de 2008, e com base nos artigos 206 e 211 da Constituição Federal, nos artigos 8º § 1º, e 67 da Lei no 9.394, de 20 de dezembro de 1996, e no artigo 40 da Lei no 11.494, de 20 de junho de 2007. Diário Oficial da União: Brasília, DF, seção 1, p. 41-42, 29 maio 2009. Disponível em: http://portal.mec.gov.br/dmdocuments/ resolucao_cne_ceb002_2009.pdf. Acesso em: 14 jul, 2015.

CAETANOS. Lei Municipal Ordinária n 109 de 2009. Dispõe sobre o Plano de Carreira do Magistério Público Municipal de Caetanos e dá outras providências. Diário Oficial do Município, Caetanos, BA, 2009.

CÂNDIDO SALES. Lei Municipal Ordinária $n^{\circ} 12$ de 2001. Dispõe sobre o Plano de Carreira do Magistério Público Municipal de Cândido Sales e dá outras Providências. Diário Oficial do Município, Cândido Sales, BA, 23 de novembro de 2001.

CONDEÚBA. Lei Municipal Ordinária $n^{\circ} 874$ de 2013. Dispõe sobre reestruturação do

ENCRUZILHADA. Lei Municipal Ordinária $n^{\circ} 858$ de 2005. Dispõe sobre o Plano de Carreira do Magistério Público Municipal de Encruzilhada e dá outras providências. Diário Oficial do Município de Encruzilhada, Encruzilhada, BA, 28 de dezembro de 2005. 
CONDEÚBA. Estatuto e Plano de Carreira do Magistério Público de Condeúba e dá outras providências. Diário Oficial do Município, Condeúba, BA, 04 de janeiro de 2013.

IBGE. Censo de 2010. Disponível em: http://www.ibge.gov.br/ home/estatistica/populacao/censo2010/default.shtm. Acesso em: 22 mar.2011.

CORDEIROS. Lei Municipal Ordinária n 554/2012. Dispõe sobre o Plano de Carreira e Remuneração do Magistério Público Municipal de Cordeiros. Diário Oficial do Município, Cordeiros, BA, 01 de outubro de 2012.

GUAJERU. Lei Municipal Ordinária no 150/2005. Estrutura o Plano de Carreira do Magistério Público Municipal do Ensino Fundamental e Médio e dá outras providências. Diário Oficial do Município, Guajeru, BA, 31 de outubro de 2005.

LICÍNIO DE ALMEIDA. Lei Municipal Ordinária nº 02 de 2014. Dispõe sobre a reestruturação do Plano de Carreira e Remuneração do Magistério, e dá outras providências. Diário Oficial do Município de Licínio de Almeida, Licínio de Almeida, BA, 25 de fevereiro de 2014.

LÜDKE, Menga; ANDRÉ, Marli Eliza Dalmazo Afonso de. Pesquisa em educação: abordagens qualitativas. São Paulo: Editora Pedagógica e Universitária, 1986.

MAETINGA. Lei Municipal Ordinária $n^{\circ} 63$ de 2009. Dispõe sobre o Estatuto do Magistério Público da Educação Infantil e Fundamental de Maetinga e dá outras providências. Diário Oficial do Município, Maetinga, BA, 2009.

OLIVEIRA, Maria Marly. Como fazer pesquisa qualitativa. Petrópolis, Vozes, 2007.

PIRIPÁ. Lei Municipal Ordinária $n^{\circ} 136$ de 2012. Dispõe sobre o Estatuto do Magistério Público do Município de Piripá, Estado da Bahia, e dá outras providências. Diário Oficial do Município de Piripá, Piripá, BA, 21 de junho de 2012.

PLANALTO. Lei Municipal Ordinária $n^{\circ} 277$ de 2008. Dispõe sobre a Aprovação do Plano de Cargos e Salários do Magistério Municipal de Planalto. Diário Oficial do Município de Planalto, Planalto, BA, 2008. 
POÇÕES. Lei Municipal Ordinária n 975 de 2012. Dispõe sobre o Plano de Cargos, Carreira, Funções Públicas e Remuneração dos servidores do Magistério Público do Município de Poções. Diário Oficial do Município de Poções, Poções, BA, 16 de março de2012.

SILVA, Daniela Oliveira Vidal. Valorização docente no território de identidade do Sudoeste Baiano: o instituído e o praticado. 2019. Dissertação (Mestrado em Educação) - Universidade Estadual do Sudoeste da Bahia, Programa de Pós-Graduação em Educação - PPGED, Vitória da Conquista, 2019.

SILVA, Jussara Borges da. A Política Nacional de Formação de Professores no Território de Identidade de Vitória da Conquista/BA: 0 processo de regulamentação da educação a distância. 2015. Dissertação (Mestrado em Educação) -Universidade Estadual do Sudoeste da Bahia, Vitória da Conquista, 2015.

TREMEDAL. Lei Municipal Ordinária n 15 de 2009. Dispõe sobre o Plano de Carreira do Magistério Público Municipal de Tremedal e dá outras providências. Diário Oficial do Município de Tremedal, Tremedal, BA, 2009.

VITÓRIA DA CONQUISTA. Lei Municipal Ordinária n 1.762 de 2011. Dispõe sobre o Estatuto do Magistério Público Municipal e o Plano de Carreira e Remuneração dos Profissionais da Educação no Município de Vitória da Conquista, e dá outras providências. Diário Oficial do Município de Vitória da Conquista, Vitória da Conquista, BA, 30 de junho de 2011.

WINK, S. E. D. A política de valorização dos docentes da rede pública de Teutônia-RS: um estudo sobre os limites e as possibilidades. 2009. Dissertação (Mestrado em Educação) - Universidade do Vale do Rio dos Sinos, São Leopoldo, 2009.

Recebido: junho/2019

Aceito: agosto/ 2019 